\title{
Achieving an Appropriate Balance between Teaching and Research in Institutions of Higher Education: An Exploratory Study
}

\author{
Mohammad Ayub Khan
}

\begin{abstract}
Achieving an appropriate combination of teaching and research as the two key elements of education offered by the institutions of higher education in the world has been and is a challenging task for the educational leadership and policy makers. Therefore, this paper is dedicated to analyze the existing theories of teaching and research integration with a purpose of: diagnosing the pros and cons of teaching and research integration; identifying implications associated with the education model based on teaching and research integration for the institutions of higher education; and finally, presenting certain specific recommendations for the institutions of higher education to achieve a better combination between teaching and research activities. The paper"s findings suggest that a balanced combination of teaching and research activities affects positively the overall education quality and standards. Nonetheless, in order to create optimal conditions for such a balanced and strategic integration between these two different but interdependent educational activities the institutions of higher education must demonstrate a strong academic and research leadership, commit all the required resources, show operational flexibility, and last but not least, build supportive institutional culture.
\end{abstract}

Index Terms-Balance between research and teaching, Benefits of research and teaching integration, pedagogy, research and teaching integration models.

\section{INTRODUCTION}

When we look at the history of the educational institutions of higher education, we find that the dilemma of how to have a balanced approach to education has never really been addressed properly by neither the education administrators and nor by the policy makers of the institution [1]. It is found that some educational institutions of higher education tend to do more teaching followed by some research efforts and continuing education. Some other universities pay a relatively more attention to the research and publication activities and teaching being the secondary function of the institution. Though they do not declare it officially or publically, however, these research universities dedicate their substantial resources (time, faculty, money) to research and publication. Highlighted in the existing research works, factors listed below are believed to influence explicitly or implicitly such strategic decisions and direction of the institution [2]-[4]:

1) The national culture of the country of origin of the university. Some national policies and programs promote

Manuscript received December 2, 2015; revised March 1, 2016. The paper was presented on IBIMA conference Madrid, Spain, November, 2015.

The author is with Tecnológico de Monterrey, México (e-mail: mkhan@itesm.mx). research and development activities and initiatives in the country and therefore, provide enough resources to the academic institutions to conduct research and development activities.

2) The university culture in itself is one of the critical factors in defining such strategies and directions. Some universities have been able to develop culture, system and process either to focus on teaching or research as the core activity of the institution.

3) Public versus private universities have also different approaches to manage their activities and functions. Private universities depend mainly on the tuition fees paid by the students as a principal source of income. Therefore, these institutions dedicate to teaching in order to provide quality education to the current and future students. Whereas public or state-run universities receive all or most of their financial resources from the public fund and with this fund they support teaching and research activities. So, it is relatively easier for such institutions to support research activities without limiting resources for the teaching activities.

4) National industrial supports in doing joint research and development works with the national universities. In developed nations including Europe and North America, for example, the nexus of government, industry, and university (especially private) is very strong in all fields, thus creating an environment of developing collaborative programs including research and development benefiting the society as a whole. In contrary to that, in developing countries the relationship between industry, government and university (especially private) is marginal or even non-existences in most of the cases.

5) Job opportunities for research graduates programs. If there are no job opportunities for researchers and even if there are job opportunities they are not well-compensated professionally and economically, therefore, students and teachers dedicate to academic programs and activities which are economically viable and profitable.

6) In general, it is believed that large size institutions have enough resource to allocate to both teaching and research. Whereas, small size institutions with few academic programs tend to allocate resources to teaching and other fund generating activities like continuing education and consulting etc.

Anyhow, the subject of how much teaching versus how much research should be done within the institutions of higher education has long been debated. Both academic managers and faculty members frequently question the idea of how much teaching and research a university professor should do 
as part of his/her normal academic workload. There is no one conclusive answer to this query though, however, to a greater extent the answer depends on the impact of research on teaching and vice versa. Some research works conducted in the field indicate that there is a significantly positive relationship between research and teaching in terms of enriching the teaching-content. However, some other research finds that such relationship may not be beneficial for the students [5]; [6] even though students do not necessarily oppose to their professors' research activities as essential to the profession rather they incline for being informed about such process [2], [7], [8]. As a matter of fact, research expectations from the university faculty have been rising for the last several decades to an extent that research productivity has become the dominant and sometimes the sole criterion for hiring, tenure, and promotion at research universities [9]-[12]. This trend has been driven by several factors including universities' growing dependence on external research funds to support basic operations and the demand or need for being ranked among the top universities in the world by national and international ranking agencies [4], [13]. Most of the research findings on this subject suggest that research activity and productivity is important for a faculty member but it does not necessarily guarantee or support quality teaching. These two activities are considered as unrelated at the individual faculty level. Some faculty members can be good researchers and at the same time they can perform quality teaching; whereas others can be excellent in doing research and publications but average in teaching, vice versa [2], [3], [14]. Having a professor with good research and teaching qualities is something ideal and for transforming ideals into reality the university management requires tremendous efforts and strong academic acumenship. Therefore, in this paper a few important questions are being answered:

1) Is it important for the higher education institutions to bring the teaching and research activities together as an effective strategy for the quality education?

2) How to achieve an optimal integration between these two different but interrelated education instruments and components?

3) What are the potential implications associated with the integration of teaching and research activities for the institutions of higher education?

\section{LITERATURE REVIEW}

In order to answer the research questions a comprehensive review of the existing literature on teaching and research education is carried out in the following sections especially, with a focus on the:

1) Similarities and differences between research and teaching activities.

2) Pros of teaching and research integration.

3) Cons of teaching and research integration.

4) Potential benefits of teaching and research integration.

5) Teaching and research integration options.

6) Pedagogical approach to teaching and research integration.

\section{A. Similarities and Differences between Research and}

\section{Teaching}

As a university professor, it is often viewed that the tasks of teaching and research are different from each other. Of course, both require dedication, motivation and resources to be performed. Both have tangible and intangible benefits for the educational institutions, teachers and students. To be a good teacher is as much important as to be a good researcher [15]. A good teacher can be a good researcher and vice versa. However, there are some specific differences and similarities between these two important components of higher education programs and services. Those differences and similarities are associated with [1], [2], [16]:

1) The objectives of and needs for teaching and research.

2) The process required to carry out teaching and research activities.

3) Resources needed to carry out teaching and research activities.

4) The impact of teaching and research on the educational institutions.

5) Qualification (knowledge, abilities) needed to perform either teaching or research.

6) The importance and benefits of teaching or research for the teacher or researcher.

Teaching and research activities undertaken by faculty can be mutually exclusive and complementary. For example, presenting a research paper at conference (national or international), giving public speeches on scientific research outcomes require exactly the same level of knowledge and skills as required by teaching a normal class. It is also helpful for the teacher to have exposure and interaction with faculty from other institutions and nationalities etc. A course management (planning, delivery and evaluation) function demands many of the knowledge and skills of research planning and development [2]. Both teaching and research help a faculty develop insight into his/her field of teaching/research, refine his/her communication skills, improve his/her ability to select and organize content in a meaningful way [2].

\section{B. In Favor of Teaching and Research Integration}

The proper integration of teaching and research activities may have positive, long term and wide range benefits for all stakeholders of educational services and programs. In particular, such integration strategy will benefit immediately and directly the two key stakeholders: students (receivers of the knowledge) and teachers (providers of the knowledge). Theories suggest that universities can benefit from integration of research and teaching by improving their good perception and public image in the eyes of their stakeholders [17]. Also, such strategies will help bringing students into research field and teachers will bring their research projects to the classrooms and both of these outcomes will further broaden the model for academic scholarship [18]. Traditionally, universities are believed to graduate students with competencies needed by the industries, which are often very much job related such as operational and managerial. Not always knowledge and skills of conducting scientific research are neither required at undergraduate and post-graduate levels for graduation nor they are needed in the industry [18].

Quality teaching is about quality learning for students and 
of course, active-quality research undertaken by a faculty can enhance quality teaching. Therefore, a strong research and teaching integration at undergraduate and postgraduate levels may produce quality teachers-researchers and quality learners-researchers. Other ideas such as linking research and teaching by inviting students into research related classes/programs and involving them in literature review, data collection and data analysis etc., or simply introducing inductive teaching methods into the class [19]. There are arguments for and against the idea of involving students in research related projects but majority in the academic and research community believe that it can help them build skills of analysis, critical thinking and writing, for instance [19].

Other thinkers claim that outstanding researchers are the best teachers as well [20], [21]. These thinkers are of the view that research professors become more closely associated with their colleagues in the same field at other universities than with faculty members within their own institution. They collaborate on joint papers, evaluate each other's work for publication in the top journals, generate offers of employment to each other, and write outside letters recommending (or not recommending) tenure for junior faculty at each other's institutions. At the end of the day, these professors share their knowledge and experiences with their students in their respective classrooms. Professors can be involved in writing quality and sophisticated papers for high impact international journals or they can write teaching materials like textbooks and students handbooks [20], [21]. The more research work professors do, the more they gain knowledge in their fields of teaching and interest. Therefore, their teaching can be more enriching, broader and original. Research based teachers are more engaging and challenging than their textbook based counterparts [20], [21].

In addition to bringing the freshest materials into the classroom, research-oriented faculty members tend to be inquisitive, demanding, evidence-oriented [21], systematic and engaging when they teach. Moreover, teaching the same subject over a number of years using the same textbook and consulting books and without new ideas, concepts and theories is a boring task both for the teacher and students. Research oriented teachers tend to be more self-confident, self-reliant and more interested in teaching since they like to share their research outcomes and self-created knowledge with their students [21].

\section{Against Teaching and Research Integration}

At this point, few questions associated with the integration of teaching and research activities need to be addressed [21]:

1) Does research-teaching integration mean to make research project part of the course content?

2) Does research-teaching integration mean that a teacher should bring his or her research-outcome to the class and share it with the students?

3) Does research-integration mean that students-teachers make up a team and do research project together (research proposal, research, presentation and publication)?

4) Does research-teaching integration mean universities should include research program in its institutional mission?
While integrating research into teaching, some researchers [22] in the field observe that it is vitally important that research activities of professors should not distract them in any way from effective teaching (pedagogy) or the contents of the course. The research activities and research subjects of the teacher should be related to the subject or area of knowledge he/she is teaching. Research is time demanding as it is commonly understood among the faculty and research community that high involvement in research projects may divert faculty attention from student-learning support activities such as advising and giving feedback on time or even preparing a good class lecture [15]. Having said that, if universities provide adequate time and resources to the faculty for teaching and research at the same time, this problem of attention diversion and time scarcity can be resolved to a greater extent.

Other studies revealed an inverse relationship between teaching and research. For example, Hattie and Marsh [2] provide three arguments for such a negative or inverse relationship between research and teaching activities:

1) Teaching and research are in conflict with each other and compete for time, energy and commitment.

2) These two activities require contrary personal orientations.

3) Research and teaching are rewarded differently and involve differing roles and expectations.

It is a widely held view in the academic community that teaching should be a first priority of all teaching institutions universities (universities, colleges or schools within the university system). Simply because too much research means too less teaching and by that it means declining teaching quality. Brew [23] identifies few barriers as described below for the faculty to be engaged in research-teaching at the same time. Definitely such barriers make it difficult if not impossible for the higher education institutions to establish a strong research-teaching bond:

1) Elements of the nature of the work (such as competing demands for time and complexity of knowledge). If the subjects taught by a professor and the subject of his/her research areas are complex then these activities may demand separate and different attention and dedication.

2) Individual characteristics of professors (such as self-efficacy, role expectations, experience/skills, personality, and beliefs about the link between teaching and research) may influence the decision of integrating research and activities.

3) Institutional characteristics such as strategic planning and management tactics, resource allocation and departmental ethos found inside a university.

4) The culture of the profession (such as value of teaching versus research and understanding of higher education). Are teaching and research activities parts of the same profession or different professions? The answer to this question may vary from an individual to individual, from an institution to institution and even from a country to country.

5) Societal culture (such as a short-run focus and perceptions of research). Some cultures tend to be long term planners, creative and innovative, and some other cultures tend to be short term oriented, less dynamic and 
lay less emphasis on research activities.

The issue of research-teaching gap and the impact of the same on the quality teaching and research need extra consideration from the school/university management [24]. The importance of research and teaching activities cannot be disputed since both of these activities and functions have far reaching impacts on the prestige and success of the academic institutions. For example, a college's prestige is based on the quality of research undertaken by its faculty and any invention or patent or reward obtained by the faculty at national and international levels is surely beneficial (attract quality students, monetary and public image) for the institution [24]. Additionally, professors involved in research and publications are better informed (updated) in their fields of teaching and therefore, students taking classes with them can learn the most up-to-date information (knowledge) in a specific field or area of knowledge. In contrary to this notion, if faculty members pay too much attention to their research and pay less attention to their classes, students may feel the difference and leave the school/college. College can have negative teaching image in the community of students and parents. Given these extreme situations, a balanced approach to research and teaching should be adopted by academic institutions while considering the following unavoidable implications associated with this approach [25]:

1) Negative impact of the diversification of the workload of the faculty on his/her performance as a source of quality teaching. This implication can be addressed as suggested earlier by allocating enough time and resources to the interested teachers-researchers.

2) Diversification of faculty activities means diversification of planning, training and evaluation. By introducing planning and performance evaluation systems which integrate all activities and consider teaching and research equally important for the institution can solve this problem. For example, teaching and research should be given equal points or credits when evaluating the performance of professors.

3) University culture usually pays more attention to the research faculty than to teaching faculty. This is an administrative and cultural issue, and can be addressed by providing the required attention to and fair treatment of the teaching activities of the institutions.

4) How to balance these activities in private versus public universities? It is possible to allocate research activities and resources to those faculty members who have the potential, interest and capacity to do research and similarly teaching activities to those faculty members who like and enjoy only teaching. It is also possible to provide necessary attention to these activities considering the needs and limitations of the institution.

5) How to compensate only teaching faculty or only research faculty? How to compensate research cum teaching faculty?

\section{Benefits of Integrating Teaching and Research}

There are several prominent benefits of integrating research and teaching activities for the teachers-researchers, students and the institutions. As suggested earlier research is an intellectual work. It can broaden the knowledge horizon of the teacher beyond his/her knowledge of the course materials and obviously teaching needs new impetus and knowledge (theories, concepts, models) and this can be achieved by doing research. Doing research and teaching may diversify the professional development opportunities for the faculty and is important for training and teaching research students [26]. The Oxford Brookes University provides rather broader explanations of why teaching and research nexus is important in many ways and from different perspectives. One basic understanding is that research is the process of learning for academics and teaching is the promotion of learning for students. Teachers learn from the research and students learn from the teachers, so there is an indirect but strong relationship between research and quality teaching. Moreover, we are moving towards knowledge-based societies and economies and therefore, research and consultancy skills are becoming key attributes in vocational and professional fields. Acquiring and building research and consultancy skills enhances graduate employability and provides graduates with the resources and confidence to understand and adapt to a society whose knowledge-base is fast changing. Students must develop these skills before they graduate and teachers must be able to transfer such skills and attributes to their students [27]-[29]. Furthermore, as never before our graduates increasingly need core skills in managing, synthesizing and deploying subject-based knowledge to derive solutions to real-world problems. Integrating teaching with research helps to embed these core skills. It is also suggested that graduates with the skills and ability to conduct research in operational settings are more likely to have the capacity to formulate problem-solving solutions (collecting information, identifying problems, finding solutions, presenting conclusions and findings). Some other benefits proposed by Jenkins, Breen and Lindsay [29] are helpful for building successful synergy between teaching and research:

1) Students learn how research within their discipline leads to knowledge creation (broadening the knowledge horizon of learners).

2) Students are introduced to current research in their disciplines (new-refreshed knowledge).

3) Students learn methods used to carry out research in their disciplines (research methods are critical for logical and systematic decision makings and finding reliable and valid solutions to the problems).

4) Students will be more motivated to learn through knowledge of and direct involvement in research (learning by doing, self-learning).

5) Students will be provided opportunities to participate in research projects conducted by their lecturers (co-learning). Plus, students learn and are assessed by methods resembling research procedures in their discipline.

6) Other benefits for students participating in research activities include that students learn how research projects are planned, organized and funded. Students become parts of the institutional learning and knowledge culture and system. Such integration of learners with research and learning at the same time, can help in forming the researchers and scholars of the future and as well as promoting research in the pedagogy of the 
disciplines.

Integrating teaching and research benefits both students and faculty [10], [11]. For example, direct involvement of students in faculty members' research as an integral part of their (clinical, practical or technical) course experiences, fosters integration of research with teaching and practice. Additionally, integrating teaching, practice, and research within the faculty role promotes knowledge development, dissemination, and application. The knowledge generated by the research works becomes accessible immediately to the students. Research activities promote critical thinking in students and for them learning becomes an exploration through active investigation. When the research focuses on topics that are relevant to the content of those courses, the faculty members can incorporate evidence from their own and their colleagues' research into the course content [10], [11]. In conclusion, researchers view that doing research is helpful in building a variety of competencies in teachers such as improving cognitive capacities, forcing rigorous in thinking and to be able to apply the principles of science and logic [8], [30], [31]. And the same competencies can be transmitted to students. Also, research plays a critical role in university governance, the creation of new knowledge causes the curriculum to grow and deepen and finally, the research-teaching interaction is essential [32], [33] for integrated educational programs and services.

\section{E. Teaching and Research Integration Options and Models}

There is no one best option or model available for universities to suit their institutional needs, interests and limitations. Scholars emphasizing upon integrating research and teaching at classroom level have identified four options or dimensions [3]:

1) Research-tutored which emphasizes on curriculum designed to promote learning focused on students writing and discussing papers or essays.

2) Research-based which emphasizes on curriculum designed to promote learning focused on students undertaking inquiry-based learning.

3) Research-led which emphasizes on curriculum designed to promote learning focused on teaching subject content.

4) Research-oriented which emphasizes on curriculum designed to promote teaching process of knowledge construction in the subject.

Levy and Petrulis [34] identify four conceptions and modes of student inquiry which if understood and recognized can be helpful while integrating research and teaching activities:

1) Information-active: Which emphasizes on students explore the knowledge-base of the discipline by pursuing questions, problems, scenarios or lines of inquiry they have formulated. Through this mode of integration an independent information-seeking is emphasized.

2) Discovery-active: Which emphasizes students pursue their own questions, problems, scenarios or lines of inquiry in interaction with the knowledge-base of the discipline. Higher order information literacy is emphasized.

3) Information-responsive: Which emphasizes students explore the knowledge-base of the discipline in response to questions, problems and lines of inquiry formulated or presented by professors. Guided information seeking is emphasized under this mode of integration.

4) Discovery-responsive: Which emphasizes students pursue questions, problems, scenarios or lines of inquiry, as formulated by professors, in interaction with the knowledge-base of the discipline. This mode of integration demands high order information literacy.

Trowler and Wareham [35] suggest a more refined framework of categories of relationship between teaching and research such as follows:

1) Learners do research.

2) Teachers do research.

3) Teachers and learners research together.

4) Research embedded in the curriculum.

5) Research culture influences teaching and learning.

6) The nexus, the university and its environment.

7) Teaching and learning influences research.

\section{F. Pedagogical Approach to Teaching-Research Integration}

It is useful to integrate research and teaching activities in universities but how to do it in practice and through pedagogy. It is important for the educational institutions to design appropriate and effective pedagogical methods to best combine research-teach functions of the faculty with the research-learn environment for students. There are various options and models of teaching in order to make this happen [36]:

1) Directly involving students including undergraduate students in research projects of the course/school or college or department. Research activity should or could be one of the graduation requirements of a certain discipline.

2) It is important that students understand the importance of research in their discipline. Before involving them, students must be informed about the importance and implications of being involved in research activities of the institutions.

3) Starting with the design of curriculum of academic programs and developing the contents of specific courses, promoting and developing research skills should be included as one of the learning objectives of the course. Teaching and learning methods such as research based learning and related techniques and skills must be explicitly included in the learning/teaching activities of a course or various courses.

4) Universities may opt for project based modules and dissertation modules as teaching methods in order to simulate research processes.

5) Research based written assignments (home-works) involving elements of research processes (e.g. literature reviews, preparing research proposals, analyzing existing data and interviews) are helpful in making students used to do research and involving students in research projects.

6) Another simple method is using one"s own personal research when designing and teaching courses and designing learning activities around contemporary research issues. 
7) Encouraging students to feel part of the research culture and projects of the school or college or department.

Some universities do ask their graduating students, especially master"s students to develop thesis which may include developing research proposal (equivalent to one full-semester course) and then actually developing the research (writing the thesis) equivalent to the credit of one full-semester course. However, the research-teaching integration model goes beyond simply asking students to write thesis at the end of their academic programs, demanding from students and teachers to be actively involved in research projects and activities of the institutions throughout the academic programs beginning from freshmen to senior levels. It sounds exaggerating the idea of research-teaching integration in a university though, however, based on the learning theories and teaching experiences it can be concluded that students can learn or learn more effectively through learning by doing methods (i.e., reading, writing on their own and discussing/sharing their study findings with their peers and teachers etc.) than simply listening to the lectures and taking notes. Education is about educating someone to keep educating himself or herself. Education is also about imparting skills and values and making the learner as a self-learner and life-long learner.

\section{DISCUSSION AND CONCLUSION}

The issue of integrating the teaching and research activities in the academia is a hotly debated but still unresolved topic. Educational institutions (schools, colleges and universities) are founded to teach, impart and share information and building competencies (knowledge, skills, values) in their respective graduates. This is a conventional as well modern understanding and appreciation of what an academic institution should do in the first place. At the same time, educational institutions are the ones responsible to create information (basic educational tool) and transfer that information to the potential users or learners. Any institutional approach to combine these two different activities in nature but similar in purpose (knowledge management) should be evaluated carefully and implemented smartly in order to achieve the value addition objective behind such an approach. Educational managers should consider these two activities as complementary to each other, rather than being competing forces or barriers to each other. Moreover, educational institutions regardless of their sizes, origins and nature are expected to do the teaching and research as core activities in an effective and efficient manner to benefit all their stakeholders. Simply put, majority university professors most of the time require to teach and do research and sometimes they are expected to do consulting or continuing education as well. Therefore, it could be a conflicting point for the faculty and students in terms of the importance given to each of these activities [37].

\section{IMPLICATIONS AND RECOMMENDATIONS}

\section{A. Implications}

In spite of the fact that combining teaching and research activities in institutions of higher education is viewed as an intelligent strategy for improving and maintaining the quality of educational services and programs, a number of impediments should not be ignored in doing so. For example:

Selecting the best option or model: Since not all teaching and research integration models suit all institutions as one size does not fit all, selecting a suitable model to fit all situations and institutions is obviously a challenging task for the leadership of a school or university. Several factors such as financial resources, availability of faculty and institutional culture are influential factors in making such strategic decisions.

Which pedagogical approach? Another difficulty in combining the teaching and research activities is deciding about the best approach to pedagogy. Traditionally universities are established for teaching mainly and other activities such as research, continuing education and community services being the secondary and tertiary activities of the institution. Making research an integral part of the pedagogy demands changes in the existing system of curriculum development, resource allocation and faculty workload distribution, a few to mention.

Strategic issues: Integrating teaching and research is not automatic and will not happen on its own since it requires a systematic and institutional approach. In order to support such initiatives, institutions should bring strategic changes at different levels [3], [22]: Institutional level policies and strategies for teaching, research, staffing and program development/evaluation; departmental level policies for staffing, workload planning and managing teaching and research, empowering academic department to developing and supporting the integration; and, designing strategies and policies at faculty and curriculum levels to integrate teaching and research functions without one affecting other negatively or inversely.

Emerging demands from various stakeholders: Demands for the quality education from various stakeholders in educational programs and services have raised the need and importance of bringing teaching and research activities together. Therefore, the promotion of inquiry-based learning, research-led-teaching and teaching-led-research are issues strongly discussed in academic institutions now a day [11]. Several factors contribute to this discussion [2], [3]: Increased pressure from parents, taxpayers, and legislators, who are unhappy or dissatisfied with the current education services and system; employer complaints about the lack of professional awareness, communication and teamwork skills in engineering graduates; challenges posed by the changing needs of our student populations and diversity in motivation, attitudes and learning styles; competencies required for $21 \mathrm{st}$ century students include problem-solving, design thinking, communication, teamwork, self-assessment, ethics, lifelong learning and other operational skills. Since, the environment is dynamic and so do the demands of the stakeholders, for institutions to keep changing themselves in order to meet those demands may become unmanageable and unsustainable.

Changing and widening environment: There are various forces associated with the changing and widening environment of the academic institutions and education sector. 
Some of those factors are [10], [38]: Schools and universities to grow and sustain growth have to be innovative, proactive and cost effective; competition for students and research resources (public money, research faculty and quality students); academic values are often traded off for economic and administrative effectiveness and efficiency; governments and universities view both teaching and research equally important; schools and universities need to: attract high caliber students into their programs and receive national and international accreditations which are costly and demand a good amount of resources.

Ownership or type of the institution: There may be a variety of ownership combinations of business schools or universities, but three types are commonly found in the literature and practice. Each of these types can have distinctive impacts on the approach to teaching and research and the degree of independence of the business school in terms of resource generation and internal policy making [39]. The first type includes private and independent institutions directly or indirectly administered by a non-governmental organization (a company, group of individuals, a community organization or church, for example). The second type refers to those public institutions which are directly or indirectly administered by a public education authority (Ministry of Education, Education Department for example). The third types are private government-dependent institutions which are directly or indirectly administered by a non-governmental organization but at the same time are dependent on the government sources [39].

Faculty conflict of interest: One dominant concern found in the academia especially, in the circle of faculty, is that the research faculty or faculty members who dedicate to research and publication are likely to gain more social status and professional prestige combined with tangible financial benefits (i.e., better salaries, research fund, travelling funds and less teaching workload). Research faculty might resist any changes affecting their status and financial benefits.

\section{B. Recommendations}

Given all the above concerns and feelings the following concrete guidelines are provided for the educational institutions to successfully integrate teaching and research activities [40]. Equally important, these guidelines can help educational institutions to promote, develop and evaluate the teaching-research activities on an equal footing inside the institutions.

1) Formally and regularly recognize and reward faculty members who successfully integrate teaching and research in their courses/classes.

2) At the institutional level, recognize and reward academic departments and programs that adopt measures to promote teaching-research integration and do it successfully.

3) Establish faculty development programs including ways to integrate these two domains: teaching and research.

4) Encourage faculty members to use inductive teaching methods (e.g., inquiry-based, problem-based, and project-based learning) and provide faculty development programs that prepare them to do so. Recognize and reward those who use the methods effectively and assess the effectiveness of the methods for integrating research and teaching.

5) Link the research projects of the faculty/department/school with the research projects/programs of government, business organizations and philanthropic organizations.

In addition to the above guidelines, it is important that universities have sufficient research/experiment laboratories; access to both printed and online research databases; and publication/editorial facilities and services. Other interesting tips in order for the faculty to integrate teaching and research at the individual level [41]:

1) Balancing time between teaching and research (time/planning for the semester/trimester/year).

2) Establishing achievable targets for teaching and research.

3) Focus on teaching and research without getting into other areas such as administrative activities or consulting projects. Avoid doing everything while doing nothing.

4) Looking for options and ways for how to bring to research activities to classroom and make it part of the learning activities of the course.

5) Sharing information and experience with other faculty members who have already integrated teaching and research successfully.

6) Having commitment, motivation and energy.

7) Using teaching methodology (pedagogy) closely associated with research such as inductive teaching and research-based learning.

8) Avoid stressful workload and allocate time for one-self.

9) Co-authoring research works (papers) with students, presenting them in conferences and publishing them in Journals and Monographs.

It is easier to say in words than actually doing it in practice and in a sustainable manner. Therefore, it is recommended for the educational institutions interested in integrating teaching-research to create an environment (culture, system, habits) conducive for faculty clusters and individual faculty to do so. A strong institutional support in forms of leadership, guidance and resource allocation are keys for such integration to happen. After all, such integrated programs should be beneficial and interesting for the faculty and students. They must be involved in designing, implementing and evaluating such programs. By imposing or forcing upon them (faculty and students) such programs might not able to take-off well-let alone to live longer.

Again, regardless of the model of organizational management and affiliation with other parent or supporting institutions, the leadership and management system of the school or university in itself can be an influential factor in making strategic decisions and defining organizational policies and programs for the institution. An academic leader: with a clear-cut knowledge of educational pedagogy and research (pure or applied); with teaching and research experience; and, with a global mindset can be and will be able to bring about any sort of changes in the organization and face off external and internal limitations by defending organizational objectives, interests and growth.

\section{Limitations IN THE STUdy AND FUTURE STUdIES}


Research experts are of the view that studies purely based on literature review are useful in identifying problems and establishing foundation for future studies in the field [42]. Such studies are exploratory in essence and therefore, lay the theoretical foundation for further scientific studies including quantitative and qualitative analyses. Moreover, literature based research are helpful in identifying needs for the research, broadening the knowledge of the researcher and clarifying the existing theories in the field of study [43]-[45]. Similarly, such studies cover review, summary and critical evaluation of the existing body of knowledge in the field, these can be helpful in constructing research questions for future studies. Literature review studies provide explanations of theories and ideas of other writers in terms of what has been written, how has been researched, what are the key issues and what to be done in future [46].

However, such research works are viewed as general, descriptive and lack field data and statistical analysis. Such research works are based on the previously published materials which are mostly textual and conceptual and thus, making it difficult to make predictions and generalize the results. Also, it is probable that the quality of research can be influenced by the researcher personal experience, rigor is more difficult to achieve and findings are difficult to understand [47]. Moreover, some researchers question the validity and reliability of the findings of such studies since research information is obtained through document analysis and secondary sources. This demands from the researcher to scrutinize and critically evaluate the source or the origin of the information used in the study.

Therefore, future studies should use quantitative methods involving field data on the integration of teaching and research activities in universities and carrying out rigorous statistical analysis in order to make the research findings more understandable and acceptable among the scientific research community. The quantitative method also enhances the validity and reliability of the research results and consequently the recommendations. Also, qualitative studies involving case studies and surveys, for example, of the existing models and their impacts on the existing university management system and the quality of education are effective research options.

\section{REFERENCES}

[1] M. A. Khan et al., Diverse Contemporary Issues Facing Business Management Education, IGI Global, Hershey, USA, 2015,

[2] J. Hattie and H. W. Marsh, "The relationship between research and teaching: A meta-analysis," Review of Educational Research, vol. 66, no. 4, pp. 507-542, 1996,

[3] A. Jenkins and M. Healey, Institutional Strategies to Link Teaching and Research, Higher Education Academy, UK. 2005,

[4] M. Q. Zaman, Review of the Academic Evidence on the Relationship between Teaching and Research in Higher Education, London, U.K.: Department for Education and Skills, 2004.

[5] E. A. Knodt, "When teaching informs research: Learning from our students," Teaching English in the Two-Year College, vol. 28, pp. 207-211, 2000.

[6] R. Neumann, "Perceptions of the research-teaching nexus: A framework for analysis," Higher Education, vol. 23, 1992, pp. $159-171$.

[7] A. H. Jenkins and M. Healy, Institutional Strategies to Link Teaching and Research, York, U.K.: The Higher Education Academy, 2005.
[8] P. Ramsden and I. Moses, "Associations between research and teaching in Australian higher education," Higher Education, vol. 23, pp. 273-295, 1992.

[9] B. R. Clark, "Teaching, research, and quality in the twenty-first century," Universities in the Twenty-First Century, Providence: Berghahn Books, pp. 98-112, 1996.

[10] B. R. Clark, "The modern integration of research activities with teaching and learning," The Journal of Higher Education, vol. 68, no. 3, pp. 241-255, 1997.

[11] J. Fawcett et al., "Teaching, practice, and research: An integrative approach benefiting students and faculty," Journal of Professional Nursing, vol. 19, no. 1, 2003.

[12] R. Neumann, "Researching the teaching-research nexus: A critical review," Australian Journal of Education, vol. 40, no. 19, pp. 5-18, 1996.

[13] A. Rugarcia, "The link between teaching and research: Myth or possibility?" Engineering Education, vol. 81, pp. 20-22, 1991.

[14] K. A. Feldman, "Research productivity and scholarly accomplishment of college teachers as related to their instructional effectiveness: A review and exploration," Research in Higher Education, vol. 26, pp. 227-298, 1987,

[15] G. Gibbs, "Institutional strategies for linking research and teaching," Exchange, vol. 3, no. 8, 2002.

[16] H. W. Marsh and J. Hattie, "The relation between research productivity and teaching effectiveness: Complementary, antagonistic, or independent constructs?" Journal of Higher Education, vol. 73, pp. 603-641, 2002.

[17] D. A. Sabitini, "Teaching and research synergism: The undergraduate research experience," Journal of Professional Issues in Engineering Education and Practice, vol. 123, pp. 98-102, 1997.

[18] J. Halliwell, "The nexus of teaching and research: Evidence and insights from the literature," Toronto: Higher Education Quality Council of Ontario, 2008

[19] M. Allen, "Research productivity and positive teaching evaluations: Examining the relationship using meta-analysis," Journal of the Association for Communication Administration, vol. 2, pp. 77-96, 1996.

[20] A. Brew and D. Boud, "Teaching and research: establishing the vital link with learning," Higher Education, vol. 29, pp. 261-273, 1995.

[21] R. Brown, "The link between research and teaching: Its purpose and implications," Innovation in Education and Training International, vol. 35 , pp. $117-129,1998$.

[22] K. Krause, S. Arkoudis, and A. Green, "Teaching-research linkages: Opportunities and challenges for practice and policy," Stimulus Paper: Carrick TRN Forum, 2007.

[23] A. Brew, "Imperatives and challenges in integrating teaching and research," Higher Education Research and Development, vol. 29, no. 2, pp. 139-150, 2010.

[24] L. Burke and B. Rau, "The reszearch - Teaching gap in management," Academy of Management Learning \& Education, vol. 9, no. 1, pp. 132-143, 2010.

[25] R. Geiger, "The home of scientists: A perspective on university research," The University Research System, Stockholm: Almqvist \& Wiksell International, pp. 53-77, 1985.

[26] M. Deakin, "The development of computer-based information systems for local authority property management," Property Management, vol. 16, no. 2, pp. 61-83, 1998 .

[27] M. Deakin, "Research led teaching: A review of two initiatives in valuing the link between teaching and research," Journal for Education in the Built Environment, vol. 1, no. 1, 2006.

[28] M. J. Prince and R. M. Fedler, "Does faculty research improve undergraduate teaching? An analysis of existing and potential synergies," Journal of Engineering Education, vol. 96, no. 4, pp. 283-294, 2007.

[29] A. Jenkins et al., Re-shaping Higher Education: Linking Teaching and Research, London: SEDA/Routledge/Falmer, 2003.

[30] K. Coate et al., "Relationships between teaching and research in higher education in England," Higher Education Quarterly, vol. 55, no. 2, pp. $158-174,2001$.

[31] L. Elton, "Collegiality and complexity: Humbolt's relevance to British universities today," Higher Education Quarterly, vol. 62, no. 3, pp. 224-236, 2008.

[32] E. Alpay and M. Jones, "Engineering education in research-intensive universities," European Journal of Engineering Education, 2012.

[33] B. Durning and A. Jenkins, "Teaching/research relations in departments: The perspectives of built environment academics," Studies in Higher Education, vol. 30, no. 4, pp. 407-426, 2005. 
[34] P. Levy and R. Petrulis, "Towards transformation? First year students, inquiry-based learning and the research/teaching nexus," in Proc. the Annual Conference of the Society for Research into Higher Education (SRHE), Brighton, UK, 2007.

[35] P. Trowler and T. Wareham, "Tribes, territories, research and teaching: Enhancing the 'teaching-research nexus,' literature review," Report to the Higher Education Academy, 2007.

[36] G. Baldwin, "The teaching-research nexus," CSHE, University of Melbourne, 2005.

[37] L. Elton, "Research and teaching: conditions for a positive link," Teaching in Higher Education, vol. 6, pp. 43-56, 2001.

[38] L. Lucas, The Research Game in Academic Life, Buckingham and Philadephia: SRHE/Open University Press, 2006.

[39] J. Zimmerman and J. Demski, On 'research vs. teaching': A long-term perspective," Accounting Horizons, vol. 14, pp. 343-352, 2000.

[40] T. Stehlik, "The teaching-research nexus in the division of education, arts and social sciences," 2008

[41] Q. Vicens and P. E. Bourne, "Ten simple rules to combine teaching and research," PLoS Comput Biol, vol. 5, no. 4, 2009.

[42] J. Anderson et al., "Positioning place: Polylogic approaches to research methodology," Qualitative Research, vol. 10, no. 589, 2010.

[43] J. Aitchison, "Access to books and journal articles by post-graduate students on a course-work master's program in information studies at the University of Natal," Pietermaritzburg, University of Natal, Pietermaritzburg, 1998.

[44] C. Bless and C. Higson-Smith, Fundamentals of Social Research: An African Perspective, 3rd ed. Cape Town: Juta, 2000.

[45] P. Leedy, Practical Research: Planning and Design, 4th ed. New York, 1989.

[46] D. B. Taylor, "What is review of the literature? Writing in the Health Sciences: A comprehensive guide," 2008.

[47] American Association of Colleges of Pharmacy, Am J Pharm Educ., vol. 74 , no. 8 , pp. $1-7,2010$

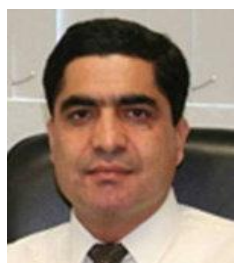

Mohammad Ayub Khan is full-professor and the director of the Marketing and International Business Department, at the School of Business, Social Sciences and Humanities, Tecnológico de Monterrey, México. He does research in the field of international business and business management education. He is the coauthor of the book: Diverse Contemporary Issues Facing the Business Management Education 